\title{
Running elicited by hypothalamic stimulation
}

MARTIN J. GERBEN, U.S. ARMY RESEARCH INSTITUTE OF ENVIRONMENTAL MEDICINE, Natick, Mass. 01760

Electrical stimulation of the posterior hypothalamus elicited wheel running in rats. The speed of running was directly related to the intensity of the electrical stimulus. Results suggest that hypothalamic mechanisms mediate locomotor behavior.

Activity wheel running is sensitive to several types of appetitive motivation (Shirley, 1929; Reed, 1947; Baumeister et al, 1964) which are mediated by hypothalamic mechanisms (Stellar, 1954; Olds, 1961). Thus, the hypothalamus has been implicated in the control of locomotor activity of the rat (Brobeck, 1955). More specifically, increases in locomotion have been associated with stimulation of the posterior hypothalamus (Scott, 1964) and lesioning of the anterior hypothalamus (Maire \& Patton, 1954). In contrast, lesions in the posterior hypothalamus decrease locomotor activity (Gladfelder \& Brobeck, 1962). In the present experiment, wheel running behavior of rats was investigated as a function of both the locus of electrical stimulation of the hypothalamus and the stimulus voltage.

Subjects. Twelve male Sprague-Dawley rats, $250-350 \mathrm{~g}$, were implanted with bipolar electrodes aimed at the posterior hypothalamus $(.75 \mathrm{~mm}$ lateral to the midline; $9.00 \mathrm{~mm}$ below the surface of the skull). Four Ss were implanted to each of the following coordinates posterior to the bregma: $2.25 \mathrm{~mm}$ (anterior placements), $3.25 \mathrm{~mm}$ (medial placements), and $4.25 \mathrm{~mm}$ (posterior placements). 1 Ss were allowed 28-35 days to recover from surgery and were maintained on ad lib food and water during the experiment.

Apparatus. Locomotor behavior was measured in a Plexiglas activity wheel, $24 \mathrm{in}$. diam and $3 \mathrm{in}$. width, mounted in a Plexiglas chamber. The distance run was measured in units of 2 in. A mercury swivel assembly mounted on the wall of the chamber allowed electrical stimulation of the brain. Solid state recording apparatus measured the distance run in units of 2 in. Electrical stimuli consisted of trains of biphasic square wave pulse pairs (pulse duration: .1 msec; interpulse interval: .1 msec; frequency: $100 \mathrm{pps}$; train duration: $1.0 \mathrm{~min}$ ).

Design and Procedure. A treatments (site of stimulation) by treatments (intensity of stimulation) by Ss design was used. The three electrode placements were described above. Ten current intensities (zero to peak voltage across the electrode) were presented ranging from 5 to $14 \mathrm{~V}$ in steps of $1 \mathrm{~V}$.

Each $S$ was initially allowed 10 sessions of free running in the activity wheel under conditions of no electrical stimulation. Each daily session lasted $20 \mathrm{~min}$. Subsequently, each stimulus intensity was presented on a different day, the order of presentation being randomly determined. Ss were run under continuous stimulation for only $1 \mathrm{~min}$ each day in order to minimize apparent muscular fatigue that had previously been observed to reduce running speed after approximately $1 \mathrm{~min}$ at the higher current levels. If at any time during a run, $S$ evidenced excessive jumping or twisting behavior which endangered the integrity of the electrode preparation, stimulation was immediately terminated and no measures of locomotor behavior were taken at or above that stimulus intensity.

Results. The distance run under each stimulus intensity is shown in Fig. 1. The data for each $S$ are plotted separately. Inspection of this figure indicates that all Ss with anterior and medial placements increased running as stimulus voltage increased. Of the four Ss with posterior placements, only number 75 evidenced this relationship.

Among the nine Ss showing increased running, only numbers 69 (anterior) and 66 (medial) completed exposure to all stimulus intensities. The runs of those Ss whose running increased with stimulus voltage were usually aborted at some intensity because of excessive jumping. Contrastingly, the runs of those three Ss that did not show increased running were terminated because of body twisting or bending backwards.
The nine Ss in which intense running was elicited could be discriminated from the three showing no effect on the basis of subsequent histological analysis. For the Ss showing increased running, the tip of the electrode was located in either the posterior, dorsal dorsomedial, or ventral dorsomedial nuclei of the hypothalamus. The Ss showing no increase in running had electrodes located in fasciculus medialis prosencephali and the fasciculus mamillothalamicus (Konig \& Klippel, 1963).

Discussion. The present results indicate that there are areas of the posterior hypothalamus which are involved in the control of running behavior of rats. Electrical stimulation of these areas results in running speeds which are directly related to the intensity of stimulation. At low or moderate intensities, Ss behaved similarly to food deprived rats. Bursts of running were observed along with increases in sniffing and rearing. At higher stimulus levels, running predominated and increased in speed and duration. At the highest voltage, Ss assumed galloping gaits of such intensity that the distance covered averaged 11.8 times the distance covered under the five voltage condition.

These results are consistent with the increases in activity cage crossings during periods of stimulation of the posterior hypothalamus previously observed by Scott (1964). Increases in locomotor activity and/or viciousness have been reported to be associated with lesions in the anterior or ventromedial hypothalamus of rats (Hetherington \& Ranson, 1942; Brobeck, Tepperman, \& Long, 1943; Arnand \& Brobeck, 1951; Maire \& Patton, 1954). Maire \& Patton (1954) view the intense wheel running occurring after bilateral lesions in the preoptic hypothalamus as resulting from the release of the posterior hypothalamus from inhibition by the frontal cortex due to the cutting of descending cortico-hypothalamic pathways. Consistent with this hypothesis are the findings of Maire \& Patton (1956) that transection of the hypothalamus just dorsal to the optic chiasm also increased wheel running while lesions in the posterior hypothalamus prevent hyperactivity associated with preoptic lesions. Gladfelder \& Brobeck (1962) report reduced locomotor activity resulting from lesions in the posterior hypothalamus. These and the present results suggest a reciprocally inhibitive relationship appears to exist between the posterior hypothalamus and more anterior structures with respect to control of locomotor activity of the rat. Such a relationship is similar to that found for appetitive behaviors (Stellar, 1954) and autonomic balance (Gellhorn, 1957). Interaction of hypothalamic activity and feeding mechanisms has recently been postulated by Routtenberg \& Kuznesof (1967) as a possible explanation for the self-starvation of rats housed in activity wheels on restricted but potentially adequate feeding schedules. The present results indicate hypothalamic involvement in the control of locomotor activity and provide a reasonable neural basis for the behavioral interrelationships between motivation and wheel running in rats.

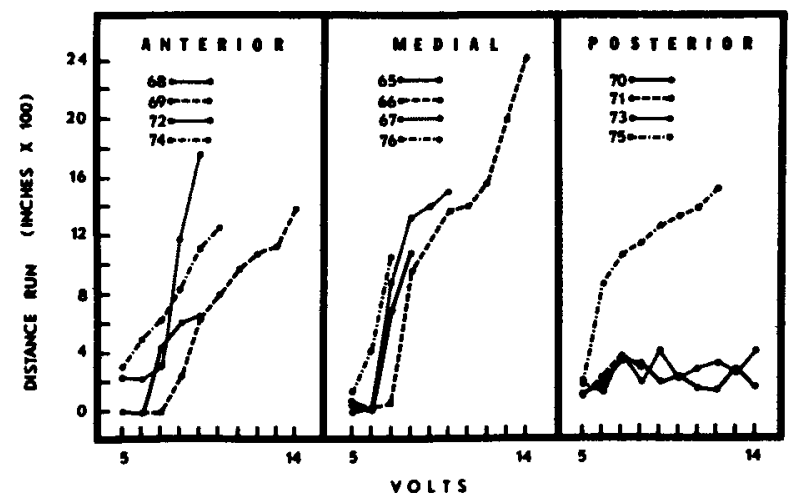

Fig. 1. Distance run by each of the $12 \mathrm{Ss}$ during $1-\mathrm{min}$ periods under various stimulus intensities. 


\section{REFERENCES}

ARNAND, B. K., \& BROBECK, J. R. Hypothalamic control of food intake in rats and cats. Yale J. Biol. Med., 1951, 24, 123-140.

BAUMEISTER, A., HAWKINS, W. F. \& CROMWELL, R. L. Need states and activity level. Psychol. Bull., 1964, 61, 438-453.

BROBECK, J. R. Neural regulation of food intake, Ann. N.Y. Acad. Sci., $1955,63,44-45$.

BROBECK, J. R., TEPPERMAN, J., \& LONG, C. N. Experimental hypothalamic hyperphagia in the albino rat. Yale J. Biol. Med. 1943, 15, 831-853.

GELLHORN, E. Autonomic imbalance and the hypothalamus. Minneapolis: Univ. of Minnesota Press, 1957.

GLADFELDER, W. E., \& BROBECK, J. R. Decreased spontaneous locomotor activity in the rat induced by hypothalamic lesions. Amer. J. Physiol, 1962, 203, 811-817.

HETHERINGTON, A. W., \& RANSON, S. W. The spontaneous activity and food intake of rats with hypothalamic lesions. Amer. J. Physioh, 1942, $136,609-617$.

KONIG, J., \& KLIPPEL, R. The rat brain. Baltimore: Williams and Wilkins Co., 1963

MAIRE, F. W., \& PATTON, H. D. Hyperactivity and pulmonary edema from rostral hypothalamic lesions in rats. Amer. J. Physiol., 1954, 178, 315-320.
MAIRE, F. W., \& PATTON, H. D. Neural structures involved in the genesis of preoptic pulmonary edema gastric erosions and behavior changes. Amer. $J$. Physiol, 1956, 184, 345-355.

OLDS, J. Differential effects of drives and drugs on self-stimulation at differential brain sites. In Sheer, D. (Ed.), Electrical stimulation of the brain. Austin: University of Texas Press, 1961.

REED, J. D. Spontaneous activity of animals. Psychol. Bull., 1929, 26 , 341-365.

ROUTTENBERG, A., \& KUZNESOF, A. Self-starvation of rats living in activity wheels on a restricted feeding schedule. J. comp. physiol. Psychol., $1967,64,414-421$.

SCOTT, J. W. Reinforcing stimulation of the brain and elicitation of general activity in the rat. Amer. Psychologist, 1964, 19, 503 (Abstract).

SHIRLEY, M. Spontaneous activity. Psychol. Bull, 1929, 26, 341-365.

STELLAR, E. The physiology of motivation. Psychol. Rev., 1954, 61, 5-22.

\section{NOTE}

1. The terms "anterior," "medial," and "posterior" do not refer to specific nuclei of the hypothalamus, but rather to the intended relative positions of the electrode placements. 